\title{
POR QUE E PARA QUÊ ENSINAR HISTÓRIA?
}

\author{
WHY AND WHAT FOR TO TEACH HISTORY?
}

\author{
Maria Terezinha Bellanda Galuch ${ }^{1}$ \\ Cleonice Aparecida Raphael da Silva²
}

\begin{abstract}
Resumo: Na sociedade atual subsiste a ideia de que o Ensino de História deve oportunizar a formação para a cidadania, tendo em vista a preservação da ordem democrática. Neste artigo, com base na Teoria Crítica da Sociedade, cujos autores destacam conceitos como esclarecimento, Educação para a emancipação, experiência formativa e pseudoformação, apresenta-se uma reflexão sobre por que e para quê ensinar História, em um contexto de fascínio e de relevância do presente. Destaca-se a necessidade de se elaborar o passado para que as condições que possibilitaram a barbárie possam ser compreendidas a fim de inviabilizar o seu retorno. Além de apontar a relevância do Ensino de História para a autorreflexão crítica, sinalizam-se possibilidades de esse ensino estimular a reflexão e a relação entre presente e passado de modo a contribuir para a compreensão do movimento da História em seus avanços e em seus retrocessos e, consequentemente, para a experiência formativa.
\end{abstract}

Palavras-chave: Teoria crítica. Experiência formativa. Ensino de história.

Abstract: In today's society, there is the idea that the Teaching of History should provide training for citizenship, aiming to preserve the democratic order. This article, based on the Critical Theory in the Society, whose authors highlight concepts such as enlightenment, emancipation oriented Education, formative experience and pseudo-formation, presents a reflection about why and what for to teach History, in a context of fascination and relevance of the present It is necessary to elaborate the past so that the conditions that allowed for barbarities are understood in order to prevent their return. In addition to pointing out the relevance of History Teaching to critical self-reflection, possibilities are shown of this teaching stimulate reflection and the relation between present and past in order to contribute to the understanding of the History's movement in its advances and its setbacks and, consequently, to the formative experience.

Keywords: Critical theory. Formative experience. History teaching.

1 Graduação em Pedagogia (1998). Especialista em Metodologia do Ensino (1993) e Mestre em Educação (1996) pela UEM. Doutora em Educação - PUC/SP (2004). Pós-doutorado Instituto de Psicologia - USP (2014). Professora do Departamento de Teoria e Prática de Ensino e do Programa de Pós-Graduação em Educação da Universidade Estadual de Maringá.

2 Doutoranda em Educação pelo Programa de Pós-Graduação em Educação da Universidade Estadual de Maringá (UEM) - Linha de Pesquisa: Ensino, aprendizagem e formação de professores. Mestre em Educação (2017), Graduação em Pedagogia (2014), Graduação em História (2000) pela UEM. Professora Colaboradora do Departamento de Teoria e Prática de Ensino da UEM. 


\section{Introdução}

Na Educação Básica, há um forte apelo para a formação de cidadãos críticos e participativos, capazes de atuar com responsabilidade na sociedade, pressupondo a aprendizagem de habilidades e competências que envolvem a competitividade, o exercício da liderança e o saber viver juntos. Essa concepção pode ser observada em diretrizes e propostas para o ensino de todas as áreas, inclusive na do Ensino de História. Essas orientações, cada vez mais valorizadas a partir da década de 1990, motivaram estudos que revelam a perspectiva de formação que perpassa propostas de ensino para os anos iniciais do Ensino Fundamental e a que projeto social buscam respostas. Pesquisas como as de Galuch e Crochík (2016), Freitas (2016) e Silva (2017) revelam que, em razão das orientações expressas em documentos oficiais alinhados à demanda de formar para a adaptação às condições objetivas, a maior ênfase recai sobre a forma de se ensinar e não no conteúdo do ensino, caracterizando-se como uma formação voltada ao desenvolvimento do homem ideal para se adaptar e contribuir para a preservação da sociedade vigente, ou seja, a ênfase é dada à modelagem de pessoas, em vez de se buscar conscientizá-las.

Tais ideias remetem à perspectiva que tornam o interesse pelo passado e, consequentemente, pelo Ensino de História, desnecessários. Posto isso, o Ensino de História se apresenta como uma questão sobre a qual precisamos refletir, levando em consideração o objetivo da Educação. Adorno (1995), considera que se fosse para definir uma meta ou objetivo de caráter universal para a Educação deveria ser a de "[...] que Auschwitz não se repita" (ADORNO, 1995, p. 119). Para se evitar o retorno à barbárie, conhecer as condições que a promoveram coloca-se como proeminente; dada a complexidade do mundo moderno, faz-se necessário pensar em uma Educação que concorra para a crítica permanente a essas condições e no quanto ainda estão presentes. Então, no "[...] contexto da escola, situada e datada - a que temos hoje" (SAMPAIO, 1998, p. 24), em que tanto se 
afirma a necessidade de formação para a cidadania e para a participação, retomar a reflexão sobre o porquê e para quê ensinar História torna-se pertinente.

Neste ensaio, temos como objetivo refletir sobre por que e para quê ensinar História, em um contexto de fascínio e de relevância do presente, com base na Teoria Crítica da Sociedade, sobretudo em estudos realizados por Adorno, Marcuse, Benjamin e Horkheimer, autores da primeira geração da Escola de Frankfurt, que destacam conceitos como esclarecimento, Educação para a emancipação, experiência e pseudoformação. Destaca-se a necessidade de se elaborar o passado, de modo a compreender o movimento da História em seus avanços e em seus retrocessos. Com isso, espera-se contribuir para que o Ensino de História, pelo trabalho com o conteúdo, possa fortalecer os indivíduos, mediante a reflexão crítica sobre as condições que possibilitam a barbárie, ou seja, que o Ensino de História possa concorrer para experiências formativas.

\section{Elaborar o passado: possibilidade de experiências formativas}

Arriscamo-nos a dizer que se Adorno estivesse refletindo conosco sobre o porquê e para quê ensinar História, talvez diria que deveríamos ensinar História para elaborar o passado e, assim, contribuir para que Auschwitz não se repita. Para o autor, a pressão que a sociedade exerce sobre os homens promove uma formação regressiva, já que o sentido de si mesmo e da realidade estão dissociados da formação humana. Nessa perspectiva, a Educação que nega o indivíduo e busca incorporar valores determinados pelos interesses econômicos é opressiva e repressiva; não fortalece a subjetividade; reforça a fraqueza do eu; não desenvolve a subjetividade, mas a consciência tutelada.

Como consequência do controle exercido pela racionalidade tecnológica, a pseudoformação passa a ser "[...] a forma dominante da consciência atual" (ADORNO, 2005, p. 2). A pseudoformação corresponde à formação que se dissocia dos bens culturais produzidos pela humanidade e dos aspectos históricos, remetendo-se à reprodução de uma ordem pré- 
estabelecida, sob a qual o indivíduo deve se formar, assim "[...] no momento mesmo em que ocorre a formação, ela já deixa de existir" (ADORNO, 2005, p. 9).

No contexto em que o presente é fascinante e a reflexão sobre por que estudar o passado - a História - se apresenta como elemento da formação, Adorno (1995) destaca que elaborar o passado é indispensável para se perceber que o presente traz elementos do passado que constituem as causas da barbárie e que podem possibilitar o retorno dela. Segundo ele, "[...] é preciso elaborar o passado e criticar o presente prejudicado, evitando que este perdure e, assim, que aquele se repita" (ADORNO, 1995, p. 11).

Benjamin (1987, p. 222), no texto Sobre o conceito de História, afirma que o passado e o presente devem ser relacionados, pois o passado comporta elementos inacabados que precisam ser atualizados para que seja construída uma experiência histórica. Para ele, "[...] articular historicamente o passado não significa conhecê-lo 'como ele de fato foi'" (BENJAMIN, 1987, p. 224). O passado deve ser "[...] compreendido como um processo capaz de explicar as principais contradições da sociedade atual" (BARROSO, 1996, p. 107).

Assim, entendemos que elaborar o passado implica reconhecer que ele permanece vivo porque, pelo fato de o presente ser histórico, guarda resquícios e apresenta condições que, uma vez conhecidas, elaboradas e eliminadas, podem concorrer para impedir o retorno à barbárie. Então, considerando-se que "[...] Auschwitz não representa apenas (!) o genocídio num campo de extermínio, mas simboliza a tragédia da formação na sociedade capitalista" (ADORNO, 1995, p. 22), a questão passa pela eliminação das condições objetivas, sociais e psicológicas que ainda podem possibilitá-lo.

Afirmar que o passado permanece vivo remete-nos à exigência de se compreender a realidade concreta. De acordo com Barroso (1996), entendê-la significa distinguir aquilo que conseguimos enxergar do fenômeno e o que ele é considerando-o em seu movimento. Em outras palavras: 
Analisar um determinado acontecimento tal como ele se nos apresenta é buscar o que ele nos mostra, que interesses e artifícios estão embutidos em sua totalidade, buscando determinar as semelhanças e diferenças, e mais importante, o que permaneceu e o que mudou. Assim devemos proceder o estudo dos modos de produção, das estruturas sociais, dos bens materiais, a superestrutura enquanto forma de organizar o poder (BARROSO, 1996, p.107).

Para Adorno (1995, p. 22), Auschwitz existiu porque existiram as condições objetivas que o geraram, da mesma forma que a persistência das mesmas condições possibilita a sua repetição. Por tais razões, se considerarmos que atualmente a racionalidade das estratégias econômicas, no auge do capitalismo tardio, permanecem gerando, por meio da indústria cultural, ou seja, da "cultura totalmente convertida em mercadoria" (ADORNO, 1995, p. 23), as condições sociais objetivas propícias à barbárie, há que não apenas refletirmos sobre elas, mas sinalizarmos possibilidades para sua superação.

A expressão 'indústria cultural' foi apresentada por Horkheimer e Adorno (1985), na obra Dialética do esclarecimento, para designar a cultura transformada em mercadoria e massificada. Os autores deixam claro que a exploração capitalista da cultura é parte do processo que estimula o ajustamento e a adaptação ao existente, provocando a coisificação da consciência. Ao se converterem em mercadoria, os bens culturais tornam-se manipuladores, também, dos sentidos atribuídos a eles e à sociedade, pois, antes mesmo de serem pensados, são subordinados aos sentidos econômicos e políticos, passando a se configurar como expressão destes. Nesses termos, Adorno (1995) considera que a gravidade do problema não incide somente sobre a organização da cultura; mas sobre a maneira como os indivíduos apreendem a sociedade, pois o esclarecimento como autoconscientização passa a ser condicionado culturalmente, limitando-se a uma experiência que, ao se restringir ao caráter afirmativo, torna-se falsa experiência, portanto não formativa. Os conteúdos veiculados pela indústria cultural são de caráter conformista, articulam-se contra a razão como sinônimo de esclarecimento, inibindo a reflexão. Assim, os indivíduos vão sendo ajustados para reproduzirem a estrutura de uma sociedade que os 
submete a um processo que orienta desde os seus sentidos e sua percepção até o seu modo de ser e de agir.

Adorno (1995, p. 22) pondera que "[...] a indústria cultural corresponde à continuidade histórica de condições sociais objetivas que formam a antecâmara de Auschwitz". Trata-se de um processo pelo qual a cultura volta-se para o consumo imediato e é disseminada pelos meios de comunicação, comprometendo a capacidade de reflexão dos indivíduos e, portanto, comprometendo a formação da subjetividade. Desse modo, o processo de formação - uma constituição inserida em um contexto histórico, político, social e cultural - é substituído pela racionalidade em que "o que se observa é a imposição do homem a um mundo que não se humaniza" (ADORNO, 1995, p. 27). A experiência instrumentalizada é falsa experiência, porque conduz à conformação, à aceitação, já que está nas relações entre sujeito e objeto a possibilidade de experiências formativas.

A experiência formativa, caracterizada pela difícil mediação entre o condicionamento social, o momento de adaptação, e o sentido autônomo da subjetividade, o momento de resistência, rompe-se com Auschwitz, que simboliza a dominação do coletivo objetivado sobre o individual e do abstrato formal sobre o concreto empírico (ADORNO, 1995, p. 26, grifo nosso).

Tais relações, de acordo com as análises de Adorno (1995), devem ser de recusa ao existente - contradição e resistência. Como Auschwitz representa não só a racionalização empreendida pelo emprego da técnica está nas experiências formativas, assentadas na reflexão, a possibilidade de rompermos com a dominação e a inserção irracional nos coletivos, ou seja, com aquilo que anula os sujeitos.

Assim, compreende-se que Auschwitz fez e "faz parte de um processo social objetivo de uma regressão associada ao progresso, um processo de coisificação que impede a experiência, substituindo-a por uma reflexão afirmativa, autoconservadora, da situação vigente" (ADORNO, 1995, p. 22); conforme afirma Benjamin (1989), estimula a vivência em oposição à experiência, tendo em conta que a experiência vivida não remete à 
memória.

Benjamin (1987), em O narrador: considerações sobre a obra de Nikolai Leskov, faz uma analogia entre a experiência e a figura do narrador, argumentando que o narrador extrai da sua própria experiência e da experiência relatada pelos outros o que ele transmite, incorporando as coisas narradas à experiência de seus ouvintes. A experiência que passa de pessoa para pessoa é a fonte a que recorrem todos os narradores. Contudo, a arte de narrar está em vias de extinção.

Benjamin destaca que a sabedoria, o lado épico da verdade está se definhando:

\begin{abstract}
São cada vez mais raras as pessoas que sabem narrar devidamente. Quando se pede num grupo que alguém narre alguma coisa, o embaraço se generaliza. É como se estivéssemos privados de uma faculdade que parecia segura e inalienável: a faculdade de intercambiar experiências (BENJAMIN, 1987, p.197).
\end{abstract}

Assim como a arte de narrar, a experiência também está em declínio. Como hoje "quase nada do que acontece está a serviço da narrativa, e quase tudo está a serviço da informação" (BENJAMIN, 1987, p. 203) explica que

[...] esse processo vem de longe. Nada seria mais tolo que ver nele um "sintoma de decadência" ou uma "característica moderna". $\mathrm{Na}$ realidade, esse processo, que expulsa gradativamente a narrativa da esfera do discurso vivo e ao mesmo tempo dá uma nova beleza ao que está desaparecendo, tem se desenvolvido concomitantemente com a evolução das forças produtivas. O primeiro indício da evolução que vai culminar na morte da narrativa é o surgimento do romance no início do período moderno. (BENJAMIN, 1987, p. 201).

Esse processo está conduzindo à "dissolução da experiência formativa" (ADORNO, 1995, p.19). Após constatar o empobrecimento da experiência, ou seja, o declínio da atividade como expressão do pensar livremente, dos sentimentos, da criatividade, da imaginação, do conhecimento acumulado, da memória individual e coletiva, e, sobretudo, da reflexão, que estão ligadas às condições objetivas, Benjamin (1989) utilizou a expressão 
'vivência' para designar "a experiência vivida" que se "manifesta na vida normatizada, desnaturada das massas civilizadas" (BENJAMIN, 1989, p. 103).

Para o autor,

[...] a experiência é matéria da tradição, tanto na vida privada quanto na coletiva. Forma-se menos com dados isolados e rigorosamente fixados na memória, do que com dados acumulados, e com frequência, inconscientes, que afluem à memória (BENJAMIN, 1989, p. 103).

Em outras palavras, a experiência, considerada por Benjamin (1989) como verdadeira e insubstituível, forma-se e se materializa mediante o conhecimento acumulado e aquilo que ficou no "inconsciente da memória", podendo ser rememorado a qualquer instante.

Experiência como sinônimo de vivência se sedimenta na existência controlada das massas, destaca Benjamin (1989). Do ponto de vista das análises de Benjamin (1989), nesse processo os sujeitos não refletem sobre as possibilidades de continuidade e de ruptura, de avanços e de retrocessos da sociedade, e, por isso, a experiência, uma atividade, na essência reflexiva, sofre restrições. Desse modo, "a criatividade, o pensar, a espontaneidade, indispensáveis à experiência, [...] são capacidades que vão se aniquilando" (GALUCH; PALAGANA, 2008, p. 75).

Como a experiência envolve a tradição, a memória viva e coletiva, a intensificação da vivência provoca o empobrecimento da "verdadeira experiência", como define Benjamin (1989), ou da "experiência formativa", como define Adorno (1995), ocorrendo o esvaziamento da memória, visto que no "mundo moderno, grande parte das energias psíquicas tem que se concentrar na consciência imediata" (PAULA, 1994, p.108). Com isso, o homem perde o contato com a tradição, transformando-se em uma vítima do esquecimento, a julgar pelo fato de a vivência inibir as possibilidades de construção de uma memória, especialmente, a coletiva.

De acordo com Benjamin (1989), a memória coletiva diz respeito àquilo que pode ser lembrado, comunicado e transmitido de geração para geração, como as histórias e as narrativas. Daí a importância de se 
esclarecer que

Quando Walter Benjamin fala do fim da narração e o explica pelo declínio da 'experiência' [...] ele retoma exatamente os mesmos motivos: a perda da continuidade entre as gerações, a eficácia da palavra compartilhada numa tradição comum e a temática de viagem de provações, fonte da experiência autêntica - mesmo que seja para afirmar que estes motivos perderam suas condições de possibilidade na nossa (pós) modernidade (GAGNEBIN, 2002, p.127).

Ao fazer analogia entre rastro (entendido como resto), memória e lembrança, Gagnebin (2002) deixa perceber que a História narrada se constitui fragmentos de um passado desconhecido, restos do que, de fato, foi ou é; preserva aquilo que serve para justificar. A autora, reportando-se a Benjamin (1989), deixa perceber que na substituição da antiga forma narrativa pela informação reflete-se o esvaziamento da experiência.

Todas essas formas, por sua vez, se distinguem da narração, que é uma das mais antigas formas de comunicação. Esta não tem a pretensão de transmitir um acontecimento, pura e simplesmente (como a informação o faz); integra-o à vida do narrador, para passá-lo aos ouvintes como experiência. Nela ficam impressas as marcas do narrador como os vestígios das mãos do oleiro no vaso da argila (BENJAMIN, 1989, p.105).

Quando buscamos evocar o passado apenas como afirmação do presente, a narrativa como sinônimo da experiência, daquilo que ficou na memória e que pode ser compartilhado, é substituída pelos 'restos de uma História' que limitam a compreensão do passado em sua dinâmica de totalidade, prendendo-se à vivência. A vivência, como aliada do progresso, aniquila e destrói a experiência; esta sim, expressão da memória e da tradição. Sem memória e sem experiência, o indivíduo perde o contato com o passado. A experiência cede lugar à inovação vista como algo em sintonia com o nosso tempo. Sem memória e sem tradição, o indivíduo adere à inovação, enaltecendo o sempre-novo.

Como a ideia de "inovar [...] supõe um grande esquecimento e um 
grande desamor face ao passado" (POMBO, 2008, p. 8), Paula (1994) aponta que "o fim da experiência e a ausência da memória no mundo moderno podem significar o início de uma nova barbárie" (PAULA, 1994, p. 113), a barbárie da inovação.

Os novos bárbaros, desprovidos de passado, vazios de experiência e de memória, têm a vantagem de se contentarem com pouco, de poderem começar sempre de novo, de serem estimulados a criar alternativas a partir de muitas dúvidas e poucas certezas, apesar de toda a sua pobreza interna e externa (PAULA, 1994, p. 114).

Em outras, palavras, os 'novos bárbaros' estão privados da 'verdadeira experiência', daquela vinculada à tradição, ao passado e ao conhecimento acumulado. Expropriado da experiência, o indivíduo se torna suscetível à adaptação e se ajusta às necessidades da vida na sociedade administrada. Considerando-se que a experiência inclui a memória, a capacidade de reter ideias, impressões, conhecimentos, envolvendo as lembranças e pensamentos que não são esquecidos, aquilo que está conservado e que pode ser lembrado, para Adorno (1995) e Benjamin (1987), deve ser o "elo entre o presente e o passado", já que se apresenta como contraponto à ordem estabelecida.

O problemático é que a ausência de conhecimento acumulado não só esvazia o passado e a experiência, como também impossibilita que seja trazido à memória aquilo que pode dar esperança. Em meio a muitas dúvidas e incertezas, contentamo-nos com pouco; ao sermos estimulados, não hesitamos em sempre recomeçar. Nesse sentido, se no passado os bárbaros saqueavam, na atualidade os 'novos bárbaros' constituem a coletividade.

No contexto da inovação, tudo o que remete à tradição, ao passado, é atacado como algo a ser esquecido, eliminado, mas não superado. Na sociedade atual, o presente é concebido como o resultado do progresso, do aperfeiçoamento, sem atentar para o fato de que esse processo envolve a dominação de uns sobre os outros, envolve a contradição: por um lado, a riqueza social é produzida em larga escala, por outro lado, perpetua-se a 
miséria humana. Assim, liquidar a memória é uma forma de o presente ser perpetuado, visto como a forma mais acabada de uma sociedade que ainda pode "progredir", mas não ser transformada.

Adorno (1995) adverte que a destruição da memória e da lembrança tende à perda da História que se evidencia no desaparecimento da consciência da continuidade histórica pelas gerações futuras. Negar o passado conduz à "autodestruição do esclarecimento, força o pensamento a recusar o último vestígio de inocência em face dos costumes e das tendências do espírito da época" (HORKHEIMER; ADORNO, 1985, p. 11), compromete a apropriação do conhecimento e, por conseguinte, 0 fortalecimento do indivíduo.

Nesse sentido, negar o passado tanto impulsiona a legitimação dos princípios burgueses de organização econômica, política e social, como representa a "decadência da forma de reagir de uma humanidade sobrecarregada de estímulos e que não consegue mais dar conta dos mesmos" (ADORNO, 1995, p. 32). A busca pelo esquecimento do passado e, consequentemente, da História, muitas vezes está ligada ao fato de o passado remeter a lembranças ruins, desagradáveis, justificando, assim, 0 desejo de nos libertarmos delas como não sendo "possível viver à sua sombra" (ADORNO, 1995, p. 29). O gesto de tudo esquecermos significa perdoar as injustiças cometidas e esse perdão reproduz, no presente, as condições que produzem as injustiças e todos os tipos de exploração e submissão (PAULA, 1994) que podem possibilitar a repetição de Auschwitz.

O passado não pode ser apagado, tampouco riscado da memória. Fazse necessário, isto sim, termos clareza se o que nos faz encará-lo com desencanto, com nostalgia, com indiferença e com indignação são suas reais condições ou se, de certa forma, ele permanece em nós, nas condições que nos cercam, apresentando-nos como uma ameaça. Ao narrar a "história de uma mulher que após assistir a uma dramatização do Diário de Anne Frank declarou: Bem, poderiam ao menos ter poupado esta menina", Adorno (1995, p. 47) enfatiza:

[...] certamente até mesmo esta foi uma declaração positiva, 
enquanto primeiro passo em direção à tomada de consciência. Porém o caso individual, cuja função era servir de exemplo do todo, converteu-se por meio de sua própria individuação em um álibi do todo, todo que acabou sendo esquecido por aquela mulher.

Isso posto, como escreve Adorno (1995, p. 46), "tudo dependerá do modo pelo qual o passado será referido no presente; se permanecemos no simples remorso ou se resistimos ao horror com base na força de compreender até mesmo o incompreensível". Há que cumprirmos a tarefa de decifrar o que há nas entranhas desses restos, do que está sendo narrado como verdade. As informações sobre o passado transmitidas por esse tipo de narração não guardam traços que permitem a crítica, daí a necessidade de serem negadas para que o mundo atual possa ser explicado e superado mediante a elaboração do passado. Enquanto as condições que geram as contradições continuarem existindo, o encantamento pelo passado mantém-se vivo.

Quando recorremos ao consolo de que acontecimentos como o da sexta-feira negra de 1929 e a crise econômica com ela relacionada teriam poucas chances de se repetir, nisto há implícita a confiança em um poder estatal forte, de que se aguarda proteção inclusive quando a liberdade econômica e política não funciona. Em meio à prosperidade, até mesmo em período de pleno emprego e crise de oferta de força de trabalho, no fundo provavelmente a maioria das pessoas se sente como um desempregado potencial, um destinatário futuro da caridade, e desta forma como sendo um objeto, e não um sujeito da sociedade: este é o motivo muito legítimo e racional de seu mal-estar. É evidente que, no momento oportuno, isto pode ser represado regressivamente e deturpado para renovar a desgraça (ADORNO, 1995, p. 41).

No contexto que sobressai a crença na tecnologia como condição para a "civilização e humanização", cuja inovação se levanta contra a tradição, expropriando o homem do saber e das relações essencialmente humanas, elaborar o passado, no sentido de torná-lo conhecido, possibilita-nos compreender os condicionantes históricos de um presente que não é novo, que se repete como reflexo de um passado não resolvido e tampouco superado. 
Ao termos clareza que a elaboração do passado é condição para que Auschwitz não se repita, não podemos perder de vista as condições que no contexto atual concorrem para a barbárie, como a formação que conduz à pseudoformação, inibindo a possibilidade de desenvolvimento da subjetividade autônoma pela via da Educação e da cultura (ADORNO, 1995), conscientes de que, em nome da inovação, não podemos desvalorizar a memória, o passado e a tradição.

Para a compreensão dos motivos pelos quais "a humanidade, em vez de entrar em um estado verdadeiramente humano, está se afundando em uma nova espécie de barbárie" (HORKHEIMER; ADORNO, 1985, p. 11), põese como necessário o conhecimento da História como movimento. Assim, poderemos nos libertar de uma indiferença embrutecida e amedrontada em relação ao passado, com vistas à construção de um novo presente. Há que se estabelecer relações entre o presente e o passado, considerando que elaborar o passado é uma alternativa contra os efeitos negativos da perda da memória e de conteúdos essenciais para o processo formativo dos indivíduos, pois sua "rememoração é reconstrução, ressignificação permanente" (PAULA, 1994, p. 109).

O conhecimento do passado possibilita, pela reflexão, compreender a realidade em movimento e as contradições que nela se estabelecem. Dado que o conhecimento construído e acumulado pela humanidade tem uma origem histórica e social, para compreender o sentido do conhecimento que nos remete ao passado, faz-se necessário analisá-lo a partir das suas relações com a totalidade. A tomada de consciência de que tudo que nos envolve tem uma historicidade, um passado que precisa ser conhecido, leva-nos à interface entre passado e presente. O passado "na medida em que é recuperado e redimensionado, transforma-se, juntamente com o presente, em ponto de reflexões e indagações" (MAGNO, 1995, p. 117), apresentando-se como antídoto para os efeitos negativos de uma pseudoformação que conduz cada vez mais à barbárie.

Adorno (1995) destaca:

[...] no capitalismo tardio, a preservação das condições 
objetivas da experiência formativa no contato com o outro e na abertura à história - ao modo de um trabalho social alternativo - é a única possibilidade de evitar a repetição de Auschwitz (ADORNO, 1995, p. 28. Grifo nosso).

Com as análises de Adorno (1995), podemos dizer que, na atual forma de organização da sociedade, o conhecimento histórico se abre como possibilidade para a compreensão das condições objetivas que impossibilitam experiências formativas. Podemos dizer, ainda, que a substituição do trabalho voltado para a satisfação e para a produção de novas necessidades, do trabalho que deforma, abre-se como possibilidade de um "trabalho social alternativo" (ADORNO, 1995, p. 28). Isso significa que "a expressão significativa da energia humana, da individualidade, da espiritualidade e da criatividade do homem" (PARANÁ, 1990, p. 82) representa uma alternativa para a transformação e para evitar a repetição de Auschwitz.

Quando guerras, conflitos étnicos e religiosos continuam ameaçando, quando avanços científicos e tecnológicos não significaram a eliminação do sofrimento, apesar de toda a riqueza já produzida, no contexto que "a fome perdura em continentes inteiros, embora pudesse ser abolida no que dependesse das condições técnicas para tanto [...]" (ADORNO, 1995, p. 40), elaborar o passado torna-se essencial.

Uma vez elaborado, compreendido, refletido, conscientizado, o passado "aponta um caminho para a re-humanização ou emancipação" (PAULA, 1994, p.108). Como o presente envolve a perda de expectativas, a decepção e, de certa maneira, a crise das certezas, um olhar mais reflexivo sobre o passado é possibilidade de entendimento da realidade posta e "apreender o presente como sendo histórico, acessível a uma práxis transformadora" (ADORNO, 1995, p. 24). Como o apego ao presente tende a tornar o homem 'autômato' (PAULA, 1994), sem consciência da verdadeira intencionalidade de tudo que o envolve, o conhecimento do passado possibilita trazer à tona discussões essenciais para a consciência histórica. 


\section{Ensino, esclarecimento e autorreflexão crítica}

Em se tratando do ensino, podemos destacar as considerações de Adorno (1995) acerca da importância de se elaborar o passado, sintetizando-as mediante uma única pergunta: qual a contribuição da História para tal feito? Hobsbawm (2007) apresenta argumentos que nos ajudam a respondê-la, destacando que

[...] sua função principal, além de relembrar o que os outros esqueceram ou querem esquecer, é tomar distância, tanto quanto possível, dos registros da época contemporânea e vêlos em um contexto mais amplo e com uma perspectiva mais longa (HOBSBAWM, 2007, p. 9).

Não se trata de organizar métodos e técnicas específicas que garantam um bom Ensino de História, mas começar a lançar luz no passado, a fim de torná-lo conhecido. Assim, o objetivo primeiro do Ensino de História deve ser "elaborar o passado", para retirá-lo "deste estado aparentemente letárgico, dessa condição de mera curiosidade, que por um longo período não conseguiu despertar qualquer interesse por parte dos educandos" (ROVAI, 1995, p. 82), ou seja, para "não deixar que o passado permaneça 'adormecido' sob os escombros da modernidade" (ROVAI, 1995, p. 82).

Em síntese, elaborar o passado requer esclarecimento; isto é, compreensão de todas as relações que os homens estabelecem entre si em diferentes tempos e espaços. Amparando-nos em Adorno (1995), não se trata de um conhecimento em si, de erudição, mas o conhecimento que possibilita a tomada de consciência, que possibilita o sujeito ver-se ao mesmo tempo como sujeito e como objeto e, por isso, buscar entender a si próprio no movimento da História e no seu próprio movimento.

De acordo com Horkheimer e Adorno (1985), para que o indivíduo compreenda a realidade que o cerca, com vistas à superação daquilo que o deforma, a reflexão deve ser a base. Segundo Galuch e Crochík (2016), é pela via do pensamento esclarecedor que o sujeito consegue entender a 
degradação da vida, o mal-estar e a frieza causada pela sociedade, os estereótipos, os controles, as falsas necessidades e o sacrifício para satisfazê-las. Com isso, entende-se que ensinar História é ensinar a analisar a realidade atual tendo como base a problematização e o estabelecimento de relações e de compreensão das contradições.

Pombo (2008) sinaliza a importância de se transmitir um

[...] saber que permita que cada geração consiga em meia dúzia de anos, aprender aquilo que de fundamental a humanidade conquistou até ao momento e que assim fique em condições de prolongar esse saber. Saberes que introduzem uma visibilidade do mundo e dos seres que o habitam (POMBO, 2008, p. 7).

Professores e escola têm como função contrapor-se à perspectiva de Educação que desvaloriza a transmissão do conhecimento universal. Com isso, não estamos defendendo que a escola não deva educar, mas que essa instituição precisa, acima de tudo, ensinar. Parafraseando Pombo (2008, p. 5), o Ensino de História não pode se limitar à transmissão de valores (saber-ser, saber-estar). Um Ensino de História que se prende à transmissão de valores, desvincula-se do objetivo que deveria ser 0 principal: o trabalho com conhecimentos que possibilitam a elaboração do passado, o que não significa desvencilhar-se de valores, mas entender quais são os valores que prezam pela vida humana e digna e não apenas pela preservação da ordem cuja exploração e exercício do poder são palavras de ordem. A luta é contra o ensino no qual o conhecimento é substituído por informações e valores que tendem a aumentar o potencial de conformação e adesão à ordem estabelecida, facilitando a ideia de "inculcar, normalizar, punir, recompensar [...]" (POMBO, 2008, p. 5).

Assim "a violência sobre o outro não é exercida propriamente sobre a vontade. A violência é exercida, agora, sobre a própria racionalidade. Vencer a razão do outro através da persuasão - Con-vencer" (POMBO, 2008, p. 5). Com isso, as práticas pedagógicas, conforme Vilela (2006), banalizando o conhecimento, propagando rituais de massificação do pensamento, "anulam a possibilidade de desenvolvimento da autorreflexão, 
de autonomia, de individuação [...]" (VILELA, 2006, p. 57). Autonomia, como conceitua Kant e esclarece Adorno (1995, p. 125), significa "o poder para a reflexão, a autodeterminação, a não-participação [...]". Ao se reduzir à transmissão de conhecimentos fragmentados, "o domínio do saber, o conhecimento da cultura humana acumulada, a reflexão sobre o próprio conhecimento" (VILELA, 2006, p. 58) vão se tornando irrelevantes. O ensino "afasta-se de seu valor essencial que seria o domínio do conhecimento, a verdadeira instrução, o verdadeiro esclarecimento" (VILELA, 2006, p. 57). Por sua vez, a formação se "converte em pseudoformação"

[...] fabrica sujeitos alienados, incapazes de uma relação subjetiva e crítica com sua realidade; a semiformação aumenta o potencial de adesão sem consciência, eleva o potencial para se reproduzir na vida social o aparente como o válido, o falso como o verdadeiro, ela expropria o sujeito de pensar e reconhecer por si mesmo o mundo real (ADORNO apud VILELA, 2006, p. 55).

Adorno (1995) esclarece que, mesmo sendo educado (escolarizado, instruído), o indivíduo não desenvolve o que é essencialmente humano: o potencial crítico e reflexivo. Uma vez destituído da reflexão, o próprio conhecimento transforma-se em armadilha, na medida em que não possibilita o pensar livremente sobre a ação, condição que "ratifica na sala de aula a coisificação do homem" (HORKHEIMER; ADORNO, 1985, p. 37), pois inibe o desenvolvimento da consciência verdadeira, condição essencial para a autonomia como base para a emancipação (ADORNO,1995).

Horkheimer e Adorno (1985, p. 18) argumentam que "no trajeto para a ciência moderna, os homens renunciaram ao sentido e substituíram o conceito pela fórmula, a causa pela regra e pela probabilidade", de tal modo que os conceitos e as imagens, categorias de base do conhecimento, como expressão de entendimento, tornaram-se objeto de descrédito, porque não podiam ser submetidos aos critérios da "calculabilidade e da utilidade" (HORKHEIMER; ADORNO, 1985). O sentido passou a ser determinado pelos interesses dominantes; o saber converteu-se em técnica em si; o fascínio 
pela técnica provocou o esvaziamento da consciência individual e a consequente coisificação do sujeito. Destituído da reflexão, o conhecimento e, por conseguinte, o pensamento perderam sua força crítica e tornaram-se pragmatistas, sem caráter superador.

Adorno (1995) estimula a reflexão, reforçando que pela apropriação do instrumental e de conhecimentos técnicos, a Educação se submete a referenciais da razão vinculados à racionalidade produtivista, cujo sentido ético dos processos formativos e educacionais é determinado por interesses econômicos. Pautando-se em estratégia científica e racional do esclarecimento, a Educação deixa de dizer respeito "à formação da consciência de si, ao aperfeiçoamento moral, à conscientização" (ADORNO, 1995, p. 16), passando a reproduzir a coerção e a dominação, inibindo as possibilidades de reflexão. Conforme o autor, "assim como o desenvolvimento científico não conduz necessariamente à emancipação, por encontrar-se vinculado a uma determinada formação social, também acontece com o desenvolvimento no plano educacional" (ADORNO, 1995, p. 15), pois a Educação, ao se prender ao princípio da razão científica e tecnológica, desvirtua-se de suas bases humanas, históricas e filosóficas.

Conforme Adorno (2005, p. 3), "quando o campo de forças a que chamamos de formação se congela em categorias fixas", como a formação para a cidadania, o processo formativo coloca-se em contradição com aquele que deveria ser o seu verdadeiro sentido. De tal forma, fortalece a cultura da pseudoformação, promovendo uma assimilação regressiva que contribui para

[...] manter no devido lugar aqueles para os quais nada existe de muito elevado ou caro. Isso se consegue ao ajustar o conteúdo da formação, pelos mecanismos de mercado, à consciência dos que foram excluídos do privilégio da cultura e que tinham mesmo que serem os primeiros a serem modificados (ADORNO, 2005, p. 6).

Para Adorno (1995), a barbárie precisa ser objeto de reflexão para que sejam conhecidas as condições internas e externas que a favorecem e, então, possam ser combatidas e superadas suas causas. Então, se 
Auschwitz é o encantamento por tudo aquilo que seduz, a barbárie pode ser entendida como pseudoformação. Nesse sentido, a questão que se coloca é: como evitar a sua repetição? Se as condições objetivas que inibem as experiências formativas e provocam a barbarização progridem na sociedade vigente, é possível reverter esse processo e possibilitar a humanização? Em outras palavras, o Ensino de História pode contribuir para a formação de indivíduos fortalecidos, capazes de resistir à ordem estabelecida?

Do ponto de vista das análises de Adorno (2005, p. 7), acredita-se que "é ainda a formação cultural tradicional, mesmo que questionável, o único conceito que serve de antítese à pseudoformação socializada". Explicitamente, a forma como está sendo proposta a formação não desenvolve a capacidade de construir relações epistemológicas mediante a realidade, condição que pode levar à perda da experiência do pensamento, deixando de valorizar a apropriação do conhecimento.

Na perspectiva da Teoria Crítica da Sociedade, a História pode ser a resistência à pseudoformação, no quanto corroborar para a formação de uma "consciência crítica e reflexiva, capaz de permitir aos indivíduos desvendar as contradições da vida social e capacitá-los para um exercício de resistência" (VILELA, 2006, p. 59) à ordem vigente, ou seja, às condições reais que permanecem reproduzindo a dominação de uns sobre os outros.

Conscientes de que isso "só é possível com o fortalecimento da autonomia, da individuação, da capacidade de enxergar o mundo sem as lentes da dominação, da capacidade de pensar e de agir por conta própria" (VILELA, 2006, p. 59), compete ao Ensino de História instrumentalizar os indivíduos para exercitarem a resistência, criando "condições para experiências individuais de autonomia de pensamento e de ação" (VILELA, 2006 , p. 61). Isso significa dizer que cabe ao Ensino de História possibilitar o conhecimento histórico, compreendendo o passado e o movimento dialético da sociedade. Mediante a elaboração, a compreensão, a reflexão e a conscientização do passado, é possível compreender as condições que geram a barbárie atreladas "às formas históricas de dominação e alienação dos indivíduos" (VILELA, 2006, p. 69), com vistas ao exercício da negação em relação ao estabelecido e à contribuição para a eliminação das causas 
que possibilitam o sofrimento.

Nesse sentido, a apropriação do conhecimento acumulado é a base, mas não só ele. No contexto em que o passado surge como se tivesse sido destruído por uma catástrofe; em que a expressão do histórico nas coisas não é mais do que o tormento passado (ADORNO, 2005, 1995) e "em que educação, ciência e tecnologia se apresentam - agora 'globalmente', conforme a moda em voga - como passaportes para um mundo 'moderno' conforme os ideais de humanização" (ADORNO, 1995, p. 11), que se anunciam, o Ensino de História se torna um elemento de formação para a resistência ao desvelar as contradições e o próprio movimento da sociedade.

A formação de uma verdadeira consciência histórica depende da forma como os conteúdos são trabalhados. Como a concretização do Ensino de História depende do conceito "como ciência", não deve se limitar a distanciar os homens da natureza, mas permitir "medir a distância perpetuadora da injustiça (HORKHEIMER; ADORNO, 1985, p. 44). Daí a necessidade de renunciar às memórias que se tornaram universais $e$ desenvolver um exercício de escuta das outras memórias que foram silenciadas, ou que, de acordo com Adorno (1995), foram 'ofuscadas', em favor de uma memória dominante.

Para Adorno (1995):

[...] aquilo que caracteriza propriamente a consciência é o pensar em relação à realidade, ao conteúdo - a relação entre as formas e estruturas de pensamento do sujeito e aquilo que este não é. Este sentido mais profundo de consciência ou faculdade de pensar não é apenas o desenvolvimento lógico formal, mas ele corresponde literalmente à capacidade de fazer experiências. Eu diria que pensar é o mesmo que fazer experiências intelectuais (ADORNO, 1995, p. 151).

Historicamente, podemos afirmar que, de acordo com Adorno (1995), para desenvolver o pensamento e a consciência histórica não se pode tomar o estudo do passado como pretexto para desenvolver o pensamento lógico formal, pois uma verdadeira consciência forma-se mediante a possibilidade 
de desenvolver a capacidade de estabelecer relações entre a realidade e o conteúdo - presente e passado. Isso implica resgatar a tradição, a experiência que, no passado, pela narrativa, era transmitido de geração a geração, podendo resultar em nova experiência, tendo em vista a valorização da memória histórica.

Por esta via, observa-se a importância de contextualização que "significa politizar os conteúdos, mostrar que estão inseridos em uma realidade" (BARROSO, 1996, p. 106), considerando que ensinar História deve ser, antes de tudo, "conscientizar. Tornar o aluno capaz de olhar uma realidade analisá-la, interpretá-la e agir sobre ela" (BARROSO, 1996, p. 106).

O estudo do passado requer que se estabeleçam relações entre o objeto de estudo e o contexto social concreto, não só para conhecer seus determinantes históricos, mas para aprender a refletir sobre eles como condição para que as causas que geram a dominação de uns sobre os outros possam ser compreendidas e eliminadas e, por assim dizer, superadas. No ato de rememorar não podem prevalecer as ideias de seleção, de distorção de conceitos e de transformação do passado, visando adequar as lembranças aos interesses de quem propõe a rememoração daquilo que passou. Marcuse (1967, p. 103-104) considera que "a lembrança é um modo de dissociação dos fatos dados, um modo de 'mediação' que quebra, por alguns instantes, o poder onipresente dos fatos dados. A memória recorda o terror e a esperança passados". Quando o passado é referido para legitimar o presente, liquidando-se os elementos perturbadores do tempo e da memória, permanece o particular no universal, a História que se quer contar; não a História que a memória preserva. Com isso, os 'temores e as aspirações da humanidade' tendem a se reafirmar e a possibilidade de que Auschwitz não se repita se esvai.

Por tais razões, compete ao Ensino de História, citando Adorno (2005, p. 18), "a autorreflexão crítica sobre a semiformação, em que necessariamente se converteu". Do Ensino de História espera-se a percepção emancipatória que busca desvelar as contradições da sociedade, desenvolver a consciência histórica sedimentada na reflexão e, assim, 
fortalecer os indivíduos, por meio da apropriação do conhecimento produzido e acumulado pela humanidade, constituindo-se em antídoto para as condições de desumanização.

O conhecimento acerca do que de fato aconteceu, com base na memória, seja individual ou coletiva, é o contraponto à História dita oficial narrada pelos livros e tido como enfadonha e desinteressante, é contraponto para o Ensino de História que impede o desenvolvimento e a formação de uma verdadeira consciência histórica.

Como esclarecem Galuch e Palangana (2008, p. 85),

\begin{abstract}
Não se trata, evidentemente, de uma reflexão pautada em vivência, em 'experiências' particulares, pontuais. Antes, sim, da reflexão guiada pelo conhecimento da sociedade, onde o particular só contribui quando tomado em relação ao universal. É esse conhecimento, considerado em sua transitoriedade - porque histórico - e em seus fundamentos sócio-culturais, que pode facultar ao sujeito uma relação com o objeto dotada de discernimento.
\end{abstract}

Nessas condições, elaborar o passado, como sinônimo de compreender o presente como reflexo dele, possibilita pôr em evidência não só o motivo pelo qual se ensina História, mas o objetivo da Educação.

\title{
Considerações finais
}

Como nos dias atuais há indícios de que, na ânsia de libertar o instante presente do poder do passado, em vez de reelaborá-lo como algo vivo, coloca-se o Ensino de História à disposição do agora, abordando-se elementos e aspectos como inspiração para um saber praticável. Um ensino que considera apenas aquilo que pode ser utilizado como material para o progresso e para a manutenção das relações sociais capitalistas contraria a formação para a reflexão e, portanto, para a experiência.

É preciso denunciar que, em nome da inovação exacerba-se o presente; com isso, nega-se o conhecimento histórico, impossibilitando a experiência do pensamento. No lugar do conhecimento histórico e da reflexão crítica, tendem a figurar propostas de desenvolvimento de atitudes 
e de habilidades fundamentais para o exercício da cidadania, o que não seria equívoco se à cidadania estivesse ligada a ideia dos direitos universais dos homens. Como exigência da sociedade e de sua forma de organização, substitui-se a apropriação do conhecimento produzido e acumulado historicamente pela introjeção de valores ligados não ao fortalecimento do indivíduo, mas à reprodução da mesma em que cada vez mais promove as condições de destruição da vida em favor da manutenção das condições objetivas e do individualismo.

O Ensino de História com ênfase na divulgação de valores entendidos como fundamentais para a preservação da ordem democrática, em substituição ao ensino e à aprendizagem de conteúdos e de valores ligados ao desenvolvimento da sensibilidade (transmissão de conteúdos característica do que se convencionou chamar de escola tradicional), tornase tão prejudicial quanto o não aprender. Quando o conhecimento histórico perde o sentido, elementos históricos importantes à compreensão do mundo, como a relação entre presente e passado, deixam de ser referidos e tornam-se estranhos. A estranheza, então, gera incertezas, tornando mais seguro aceitar aquilo que é familiar, ou seja, aquilo que tem relação com o presente - a repetição, a permanência.

Da perspectiva da Teoria Crítica da Sociedade, acredita-se que o Ensino de História precisa superar a finalidade que Ihe tem sido imposta de formar para a cidadania formal - porque, a Educação não tem o direito de "modelar pessoas a partir de seu exterior" (ADORNO, 1995, p. 141), tampouco de se restringir à "mera transmissão de conhecimentos" (ADORNO, 1995, p. 141), cabendo-lhe "a produção de uma consciência verdadeira" (ADORNO, 1995, p.141), por meio da autorreflexão crítica, tal como deixa perceber Adorno (2005).

Isso não significa a defesa da volta ao passado e nem mesmo abrandar a crítica a ele, mas reforçar que a "perda da tradição, como efeito do desencantamento do mundo, resultou num estado de carência de imagens e de formas" (ADORNO, 2005, p. 9) que inviabiliza a formação capaz de conduzir à "autonomia e, portanto, à emancipação" (ADORNO, 1995, p. 173). Como uma Educação para a autonomia e para a emancipação 
pressupõe uma formação para a conscientização, esta deveria se constituir o primeiro objetivo do Ensino de História. "Isto seria inclusive da maior importância política" (ADORNO, 1995, p. 141), pois conforme o autor "uma democracia com o dever de não apenas funcionar, mas operar conforme seu conceito demanda pessoas emancipadas. Uma democracia efetiva só pode ser imaginada enquanto uma sociedade de quem é emancipado" (ADORNO, 1995, p. 141). Considera-se que "uma democracia não deve apenas funcionar, mas, sobretudo trabalhar o seu conceito, e para isso exige pessoas emancipadas. Só é possível imaginar a verdadeira democracia como uma sociedade de emancipados" (ADORNO, 1995, p. 1); pessoas que compreendendo o passado podem livrar-se do presente como a única forma de existência. "Precisamos construir um conceito de História que corresponda a essa verdade" (BENJAMIN, 1987, p. 226).

\section{Referências}

ADORNO, Theodor Wiesengrund. Educação e emancipação. Tradução de Wolfgang Leo Maar. 2. ed. Rio de Janeiro: Paz e Terra, 1995.

ADORNO, Theodor Wiesengrund. Teoria da semicultura. Primeira Versão, Porto Velho, v. 4, n. 191, p. 1 - 20, 2005. Disponível em:

http://www.primeiraversao.unir.br/atigos_pdf/191_.pdf. Acesso em: 18 mar. 2019.

BARROSO, Vera Lúcia Maciel. O ensino de História: qual metodologia? Revista da Faculdade de Porto Alegrense. Educação, Ciências e Letras, Porto Alegre, n. 16, 1996.

BENJAMIN, Walter. Magia e técnica, arte e política: ensaios sobre literatura e história da cultura. São Paulo: Brasiliense, 1987.

BENJAMIN, Walter. Sobre alguns temas em Baudelaire. In: BENJAMIN, Walter. Charles Baudelaire um lírico no auge no capitalismo. São Paulo: Brasiliense, 1989. p. 103-149.

FREITAS, Vinícius Adriano de. Letramento, alfabetização e formação cultural (BILDUNG): sobre métodos, propostas de aquisição da língua escrita e livro didático de alfabetização para o $1^{\circ}$ ano do Ensino Fundamental. 2016. Dissertação (Mestrado em Educação) - Universidade Estadual de Maringá, 2016. 
GAGNEBIN, Jeanne Marie. O rastro e a cicatriz: metáforas da memória. ProPosições, São Paulo, v. 13, n. 3, p.125 - 133, set./dez. 2002. Disponível em:

https://periodicos.sbu.unicamp.br/ojs/index.php/proposic/article/view/8643 942/11398. Acesso em: 18 mar. 2019.

GALUCH, Maria Terezinha Bellanda; CROCHÍK, José Leon. Propostas pedagógicas em livros didáticos: reflexões sobre a pseudoformação. Cadernos de Pesquisa, São Paulo, v. 46, n. 159, p. 234 - 258, jan./mar. 2016. Disponível em: http://www.scielo.br/pdf/cp/v46n159/1980-5314-cp46-159-00234.pdf. Acesso em: 18 mar. 2019.

GALUCH, Maria Terezinha Bellanda; PALANGANA, Isilda Campaner.

Experiência, cultura e formação nos contextos das relações de produção capitalista. InterMeio, Campo Grande, MS, v. 14, n. 28, p.71 - 87, jul./dez. 2008. Disponível em:

http://www.intermeio.ufms.br/revistas/intermeio28.html.

http://seer.ufms.br/index.php/intm/article/view/2490/1683. Acesso em: 1 jul. 2019.

HOBSBAWM, Eric. Globalização, democracia e terrorismo. Tradução de José Viegas. São Paulo: Companhia das letras, 2007.

HORKHEIMER, Max; ADORNO, Theodor Wiesengrund. A dialética do esclarecimento: fragmentos filosóficos. Tradução de Guido Antonio de Almeida. Rio de Janeiro: Zahar, 1985.

MAGNO, Maria Ignês Carlos. Sala de aula: espaço de revelações: prova: ponto de reflexões. Comunicação e Educação, São Paulo, v. 2, p. 116 - 122, jan./abr. 1995. Disponível em: http://www.revistas.usp.br/comueduc/article/view/36144/38864. Acesso em: 18 mar. 2019.

MARCUSE, Herbet. O fechamento do universo da locução. In: MARCUSE, Herbet. A ideologia da sociedade industrial. Rio de Janeiro: Zahar, 1967. p. $92-141$.

PARANÁ. Secretaria do Estado de Educação. Currículo básico para a escola pública do Estado do Paraná. Curitiba: SEED, 1990.

PAULA, Fátima de. Tensões e ambiguidades em Walter Benjamin: a modernidade em questão. Plural; Sociologia USP, São Paulo, n. 1, p. 106 130, 1994. Disponível em:

http://www.revistas.usp.br/plural/article/view/68057/70627. Acesso em: 18 mar. 2019.

POMBO, Olga. Elogio da transmissão. 2008. Disponível em: http://cfcul.fc.ul.pt/biblioteca/online/pdf/olgapombo/elogiodatransmissao.p df. Acesso em: 18 mar. 2019. 
ROVAI, Marta Gouveia de Oliveira. Os meios de comunicação de massa nas aulas de história. Comunicação e Educação, São Paulo, v. 3, p. 81-87, mai./ago. 1995. Disponível em:

http://www.revistas.usp.br/comueduc/article/view/36163/38883. Acesso em: 18 mar. 2019.

SAMPAIO, Maria das Mercês Ferreira. Um gosto amargo de escola: relações entre currículo, ensino e fracasso escolar. São Paulo: EDUC, 1998.

SILVA, Cleonice Aparecida Raphael. Por que ensinar história? o ensino de história nos anos iniciais do ensino fundamental. 2017. Dissertação (Mestrado em Educação) - Universidade Estadual de Maringá, 2017.

VILELA, Rita Amélia Teixeira. A teoria crítica da educação de Theodor Adorno e sua apropriação para a análise das questões atuais sobre currículo e práticas escolares. Minas Gerais: PUC-Minas, 2006. Relatório final de pesquisa 2004-2006. Disponível em:

http://portal.pucminas.br/imagedb/mestrado_doutorado/publicacoes/PUA_A RQ_ARQUI20120828100151.pdf. Acesso em: 18 mar. 2019. 